\title{
A SIMULATION STUDY FOR THE DESIGN OF AN AIR TERMINAL BUILDING
}

Samuel Eilon and Stephen C. Mathewson

Department of Management Science, Imperial College, Exhibition Road, London, SW 7 2BX.

A.bstract

The paper considers the use of simulation in the design of an airport passenger terminal building. Results from a typical study are shown and discussed. The conclusion is drawn that whereas a conventional simulation approach offers many advantages in describing reality, the cost and complexity of analysis make it an impractical operative tool. Instead a simpler method is suggested, which may be used in conjunction with simulation or in its own right. The paper discusses the implications of this method for:

1. Design and evaluation of a model

2. Reduction of variance and improved efficiency in use of simulation

3. Integrated real-time management/computer control.

\section{Introduction}

The design of airport terminal buildings has been investigated by a number of authors, including Chamberlain and Micka [3], Smith and Murphy [16] and Speas [17]. It appears from these papers that the utility of the complex models used has been generally low, apparently because the cost of the analysis was rather prohibitive. In this paper we illustrate the use of simulation for the study of a complex problem, and show how this experience has suggested a revised approach to the design, analysis and use of the technique. The new concepts are based on the use of a relatively simple model, and perhaps may be considered as a natural extension of the application of control tools (see Gaver ${ }^{7}$ and Tocher ${ }^{18}$ ).

The paper falls into four parts which follow the chronological introduction of these concepts insofar as they were triggered by the study.

In the first section we review a simulation of an airport terminal building and consider the difficulties in the strong time dependence of the observations, and in the multiple input and control factors. In the literature the former problem has been treated through spectral analysis or through the application of the appropriate coefficients to correct for the effects of autocorrelation on the estimation of variance 5,8 . But these techniques all imply that the observations have a covariance stationary property. This disqualifies their use in this context, where the strong time dependence similarly prevents the use of response surface techniques in the analysis of the multiple factors.
As a result of these inadequacies a further model was derived. This is described in the second section.

At the same time the problems introduced during the design of the model in the presence of a very complex real world system have led to a reappraisal of the methodology suggested by Naylor, Balinty, Burdick and Chu ${ }^{14}$. In general terms this affects the ordering of the deșign process, but within the separate stages there are further implications for the validation. This forms the third section of the paper.

In the fourth section we discuss the use of the simpler model to improve the efficiency of analysis for the results generated by the simulation. Both the final sections are related to the use of the simpler model.

\section{The Terminal Building Model}

\section{Introduction}

An air terminal building is a complex of several operating systems and the design of such a building needs to take into account the following factors:

1. A quasi-random pattern of traffic - schedules of a eroplane arrivals and departures have numerous constraints, some emerging from limited physical and environmental facilities and others relating to preferred departure and arrival times at other airports; in addition, a random element is superimposed on the schedules as a result of operational, engineering and air traffic delays.

2. Passenger characteristics - passengers vary in their needs and behaviour.

3. Interaction between functions in the building some functions are under the jurisdiction of the BAA (British Airports Authority), some are the responsibility of other autonomous bodies. The various bodies closely interact, and at times may be in conflict for resources (eg space) within the building.

4. Complex operating procedures - many functions in the building must follow specified; procedures, some of which carry statutory requirements and these procedures affect the interaction between functions and impose inflexible demands on the terminal building. 
Conflicting objectives - passengers, the BAA, the airlines and the other bodies responsible for passenger processing all have their own objectives and criteria by which they judge operational performance at the airport, some of these objectives are bound to be in conflict and yet the designer of the building must account for this diversity.

The processing of arriving or departing passengers may be described as a large queueing system, consisting of sequential queues and elaborate flow patterns. But the system is too complex to be analysed by queueing theory, both on account of the size of interactions of nodes in the network and because of the transient nature of the operation. The study reported in this paper ${ }^{12}$, which has been carried out at Imperial College, was initially based on the use of simulation, leading to the development of further models.

\section{The Model}

The model selected for the study is a simplified version of the passenger arrival side of the Number Three Terminal Building at London Airport, Heathrow. The physical layout of the building represents the structure as it was before the opening of the new arrivals section and the B-747 extension. The level of manning at the various controls is arbitrarily selected and the input pattern is approximately that for the summer of 1970 . The model is hypothetical and the results - which are rather poor - must not be regarded as criticism of any department or facility in the building. In order to allow a consistent comparison ve have removed the variability in service time. The model assumes a group size of 1.6 persons as input.

The flow patterns of the passenger handling are those shown in Figures 1 and 2 . The manning levels are assumed to remain constant during the time under investigation.

The basic data for the preliminary run are shown below:

80 seat airline coaches (airside)

Port Health receptionists

Immigration Controllers (UK)

Immigration Controllers (A.lien)

Customs Officers (exercising 100\% check) 12

47 of the stands on the apron around the building are assumed to be serviceable, and only available for inbound aircraft. The areas associated with the ground handling agents of the user airlines are considered to be typical of 1969. Generally this implies that BOAC and Pan American handle the traffic at the east and west ends of the building respectively, that Air Canada is completely away from the pier served stands and that other airlines are allocated to the remaining areas.

The data which were kindly made available to us by the B-747 users committee, represent predictions of traffic in the summer peak of 1970 .
Operation and Output

One argument suggested for the use of simulation in this study is the advantage which this method offers for presenting results in graphical form. This is demonstrated by the output shown in Figures 3-9.

The diagrams represent the level of congestion encountered by inbound passengers at specific points in the system, and show how congestion varies with the time of day: Figure 3 shows the number of passengers arriving at the building during each five minute period (note the major'surge around $7.00 \mathrm{am}$ ). Figure 4 shows the total number of passengers in the building walking along the finger piers or waiting to disembark from their aircraft. Figure 5 records the queue size at the central Port Health control. This gives a maximum queue length at 7.05 am and 7. $30 \mathrm{am}$, but it is no larger than 64 people ( 40 groups with an average of 1.6 passengers per group). Because these measurements are taken at regular and discrete time intervals they do not provide an exact estimate of the maximum queue size and one problem is to describe the limits of variation of the queue size. $^{\mathbf{X}}$ Figure 6 shows the queve build-up at Alien Immigration (the maximum congestion occurs at 8.15 am with approximately 336 passengers waiting for service) and Figure 7 describes the UK Immigration Control. Figure 8 demonstrates the congestion at baggage reclaim (the pronounced drop at $7.40 \mathrm{am}$ arises from an assumption in the program that if a passenger is present, his baggage may be collected as soon as it is delivered into the reclaim hall (it is further assumed that all baggage reaches the carousel approximately 17 minutes after the arrival of the aircraft)). Figure 9 shows congestion at the customs (note that the scale has been changed because of the size of the queue build-up).

Congestion at Customs control is clearly excessive. An alternative manning policy, selected intuitively, is as follows:

Port Health receptionists Immigration Controllers (UK)

$\begin{array}{cc}\text { Change } & \text { New level } \\ -2 & 2 \\ +1 & 2 \\ -2 & 6 \\ +3 & 15\end{array}$

The results of this revised manning level are shown by dashed lines in the relevant figures. At Port Health we have an increase in queueing levels, shown in Figure 5. As expected, Figure 6 shows a considerable increase in the queue size at Alien Immigration, but the reduction in manning here (combined with that at Port Health) helps to reduce the level of congestion at baggage reclaim (Figure 8), since passengers are now more likely to find that their baggage is available for collection at the carousels. Furthermore, the increased service capacity available at the Customs control, with the 15 duty officers, coupled with the reduced rate of flow into the control area, is reflected in the reduced level

"The implications of "time slicing" with respect to the estimate of mean values are discussed by Gafarin and Anker ${ }^{6}$. 
of congestion in the Customs Hall (Figure 9).

The progress of individual passengers through the system can also be traced and histograms of waiting times can be obtained. The new proposed manning level is expected to reduce the time speat by passengers in the system (as shown in Figure 10), although the new waiting time is still too high.

For flight operators, such global results are not adequately informative, and a breakdown for each flight may be given.

While examples cited here do not provide comprehensive information about the works of the system (for example, they do not show the total amount of baggage stored on the carousels, and this amount is bound to increase under the modified scheme) they are sufficient, we believe, to illustrate that results from simulation runs can be presented graphically in a form that is easily comprehensible to analysts and to managers alike, thereby providing an effective tool for examining the performance of a system and evaluating alternative proposals for modifying its operation.

\section{Analys is}

As an example of data analysis consider the problem of estimating for each flight the mean passenger delay (hereafter referred to as the delay). In vi ew of the time dependence, we seek to identify an input-output transformation. We will assume a constant model format and a known arrival schedule.

Regression appears the most appropriate technique to employ. During the analysis of the simulated results a number of models were tested. Initially the delay was considered a function of the aircraft payload, but results proved to be poor, because aircraft arriving before the one considered had already caused congestion in the system. Thus we decided that a more comprehensive input history must be taken into account.

The method selected reflects the mechanisms within the system whereby the delay experienced by a man in a queue is a function of the queue length and the service rate. It is similar to that of Carlin and Park ${ }^{2}$ who in a study of runway delays, use a set of difference equations to relate queue length to the arrival rate and the service rate.

If pàssenger delay is plotted against congestion in the building, the slope is an estimate of the appropriate coefficient in the equations.

The validity of the method was checked against many conditions of flow and two examples are shown here. In Figure 11 the flow is relatively well ordered with no points of heavy congestion. The variance a about the line is small, showing the validity of the original assumptions of the relationship between congestion and delay. However, Figure 12 shows the situation in which there exists heavy congestion at Alien Immigration control, and here the variance about the regression line is large. Thus in general total congestion may be related only weakly to delay and the utility of any predictive model based on these as sumptions must be low.

It has been argued that the whole system may be regarded as a global single queue, where the throughput time (which is the time spent from entry to exit) consists of waiting time and global service time and any new arrival to the system will have to wait until all previous arrivals have been processed (assuming a first-come-first-served queueing discipline). In fact the flow through the system is not that well ordered. Passengers may by-pass Port Health, or may join the UK Immigration Control which gives faster service than a congested Alien Immigration Control. Thus, paths of passengers through the system represent routes in a network with converging and diverging flow through parallel and sequential queues, each with its own characteristics. A method of solution evolved to handle this problem is described in the next section.

\section{A Model of a Complex Network}

The regression model of the airport was then replaced by a network as shown in Figure 13 and this compared with the results that were obtained from the simulation. Specifically we show the results for the conditions of high congestion at Alien Immigration, for which the previous regression model proved unsatis factory.

The input points consist of two pairs of nodes 1 and 2 and nodes 3 and 4 . Each pair provides a source for UK and alien passengers. Nodes 5 and 6 then feed the combined flows into the system as though from an aircraft exit door. The two apparent inputs 5 and 6 are selected as the minimum number of nodes required to prevent spurious interference between flights and yet minimise the number of nodes used. Node 7 represents the point where the merged input begins to diverge. The four nodes 8-11 are selected to reflect different expected delays associated with walking to the central area and result from the four handling agents specified in the simulation model. Nodes 12 and 13 represent UK and Alien Immigration Control points, node 14 the Baggage Reclaim area and node 15 Customs Control.

A value is given too for each node corresponding to its maximum service rate. Where a control point has $n$ servers with a mean service rate of $\mu$ per server the rate for the node is $n \mu$. The values to be given to simple delays are more difficult to determine since they represent both walking and coaching, and whereas walking delay is independent of the size of the passenger group, travelling by coach is not. Thus the delay of passenger is made up of:

Note that the variance about the line may be shown to to be a function of the congestion. Therefore, used in a predictive sense the model cannot be given rigid confidence intervals. 
1. Queueing to leave aircraft

2. Queueing (if any) to board coach

3. Waiting for coach to leave

4. Journey time from stand

5. Queueing to leave coach

6. Walking to eentral area.

The duration of activities 2, 3 and 5 depend upon the size of the flight and the availability of a coach. An average $\eta$ is adopted, which is a function of the stands which are specified for use by the flight (see section 2, introduction): The program for the network is denoted by the acronym CARN (E onditional Analysis for Random Networks): It fulfills the following functions:

It will describe any network having poth convergent and divergent paths, up to a limit of 16 or 32 nodes depending on the word size of the computer used. The flow through the network is unidirectional and the shape is speeified as initial data.

It will accept input in the form of batches of units. Each batch will have a specific path through the network. Batghes may be combined at input if it is required that units of the same input follow different paths; for example UK and A lien passengers off the same flight.

It will process units through the network and correct for the stochastic nature of flow and service, Each period of seryice is viewed as a transient occurence and the appropriate coefficient is taken as a function of the batch size and local traffic intensity. The accuracy of the model improves as congestion increases.

(4) The units are identified by their batch flow characteristics fathen than as individuals: In this way there is a substantial reduction in core requirements over the simulation.

When the programhad been eqmpleted a series of comparisons were made between simulation models and their equivalent CARN networks: A sample network and output are shown in Figure 14 and Figure 15. Note that the computing requirements are Simulation - 17.9 mins., CARN program - 0.78 mins.

The estimated values from CARN are compared with the simulation output in Figure 16. The large error is attributable to the fact that the network model assumes a uniform split petween UK and alien passengers taken oyer each flight whereas in the simulation the splits for individual flights vary considerably from the ayerage. When the actual figures are used as the input to the network, the results improve considerably, as shown in Figure 17 . Moreover, compared with Figure 12 we find that the maximum scatter is reduced from approximately 160 to 20. A complete investigation 12 shows that the CARN technique mąy be justified where;

Conflict between batches of the input for resources in the system plays a major role ele, and

\section{Congestion is high.}

\section{The Design of a Simulation Study}

Many authors have discussed experimental design for simulation, few have considered a strategy for the total implementation of a study. Typically the methodology is that of Figure 18. The experience of the relatively complex airport investigation suggests that Figure 19 is a more appropriate series of steps, which we review later. We also suggést a secondary class of model for the general queueing problem in the form of the CARN program which may be considered as the secondary model suggested by Lave and Taha 11 or as "complementary research" in the context of Van Horn's recent paper on validation of simulation results. 19

\section{The Objectives}

We may categorise the purpose of a simulation as explorative, predictive or operative.

The explorative model seeks to review and highlight the behaviour of the system, usually in qualitative terms and involving a high degree of involvement by non-OR specialists. 13 The bias of the model must ther efore emphasise the iconic character of simulation. A predictive model is one that seeks to answer the question "what happens if ?" or it compares the behaviour of the system under alternative operating conditions. Here the dominant requirement is sufficient flexibility - which is best provided at the initial stage of model design. As an operative tool the model may be required to produce optimal solutions to given problems, for example it may be asked to design the best layout for given patterns of arriving or departing passengers, or to alter the arrival schedules in order to smooth the load on facilities in the building. Such an optimisation might be incorporated in a simulation model provided a search algorithm is available for scanning a suitable set of alternatives.

For this purpose, the program must be fast and an efficient search routine must then concentrate on the most sensitive parts of the model by restricting the factors considered to some arbitrary set consistent with the resolution attainable in the search. For example, some random elements in the arrival process may increase the number of samples to be taken for a given level of confidence and thereby increase the cost of detecting small changes in the expected values, without themselves altering the expected values.

The main use of the operative model lies in the field of control, particularly with the growth of on-line terminals and direct access to real-time computation. The purpose of the program is to present better quality 
information to the Manager within the normal time period available for an operational decision. These requirements are synonymous with those of the optimising objective in that speed is required with the extra problem of the interface between man and machine. The model must be fast, not necessarily highly accurate but it must perform consistently well over the whole operating range, both when the system is uncongested and when it is highly congested. This is not a trivial requirement. In a complex situation there are many elements which may be minor and irrelevant in normal circumstances but become vitally important in certain extreme conditions, and these must be identified and incorporated into the model.

These requirements are not consistent with the sampling methods of a Monte Carlo model. However it appears to us that a combination of simulation and an appropriate secondary model, such as CARN, can be usefully employed. The simulation would be used to monitor the performance of the secondary model, which is included in the optimising routine.

\section{Defining the logic of reality}

The second stage in the construction of the model is to observe and codify the behaviour of the system in the real world. There are two levels at which this may be reported. Figures 1 and 2 show the activities associated with the arrival of aircraft and the flow of passengers through the building. This type of presentation, breaking the activity into classifications according to the type of control exercises, is of value when we wish to explore possible changes in the system, in order to identify those areas where flexibility should be incorporated into the model and those controlled by statute where flexibility is not relevant.

The general concept of a diagrammatic presentation of the modeller's perceptions is very important in providing an effective dialogue between the modeller and the manager. Errors found at this stage are the cheapest to rectify. The entity-activity charts, developed by Hills ${ }^{9}$ are amongst the most useful tools for this stage.

Concurrently with the review of the logic of the real world it is usual to collect the data of the operational characteristics. Consider the one passenger activity of leaving the aircraft. This could be a function of the aircraft, the airline; the internal seating configuration, the route (North Atlantic travellers, like commuters, carry little luggage; those from South America tend to be travelling for personal reasons and have more luggage), the time of day or night, the type of airstairs and possibly the weather. In short there are an immense number of permutations. The use of a rough model, embracing the whole system, can give a useful first order measure of data sensitivity. Although in any event we believe that the expense of a total field survey should be incurred as late as possible in the study, when the researchers have some value of the cost-effectiveness of the collection effort. Initially measures of the mean and dispersion should be adequate.
The design of the mode1

In general terms a simple model which is fast to run and for which are readily available is preferable to a complex model as an operative tool. But the simple model may lack accuracy.

There are practical problems in. introducing simplicity into the model in well-defined situations, as in the case of Port Health. At the simplest level we may consider this function as a service point with parallel servers, placed in the main stream of passenger flow. All Port Health passengers are then assumed to pass through this control point, and those referred to the doctor will then be ignored. In this way we simply associate passenger delay at the Port Health function with the time spent at the receptionist. For a more sophisticated approach we can incorporate the effect of the service offered by the Port Health doctor on the total delay experienced by the passengers before they rejoin the main flow.

In contrast, we have an ill-defined situation at the Customs area. If a passenger is stopped and searched, the duration of the search may be statistically dependent on various factors such as:

- the queue length in the hall

- the length of the previous idle period

for the officer

- the origin of the passenger

- the total time the officer has been working on the shift

and so on. Many of these variables are measurable, but it may be difficult to relate them to attributes of the system, and the modeller needs to decide which should be incorporated into the program. Here, as in the data collection exercise, an alternative model of the total system interactions may usefully evaluate the sensitivity of the global parameters to the local accuracy required in the specification of the simulation logic.

\section{Writing the program}

The computer program was written in SIMON, a FORTRAN based computer simulation language, which has been developed at Imperial College. 10 ? In return for a greater programming effort, the language offers a greater degree of flexibility than can be obtained from a standard package language. Conceptually it is equivalent to GASP II.

'This in turn may be extended by relating the availability of the doctor to the total demand on his services, which may be associated with

- the number of sick passengers, who become ill with other than a communicable disease

- the number of emergency cases arising from the general public, or

- the number of passengers referred to the Port Health unit by the Immigration control. 
The most difficult part of the study is validating the model. Traditionally this is accomplished through back-casting, that is by comparing the behaviour of the model with known behavioural patterns in the past.

But the simulation of a complex system has many facets and validation implies the measurement not only of the input data, but of a wide range of typical output parameters such as queue lengths, passenger delay distributions and the load on servers at queueing point. 15,19

Such measurement is expensive; within many existing buildings to observe the complete range of operating levels is infeasible and, if the building is yet to be build, quite impossible. In these circumstances it is necessary to seek general measures and to adopt sensible assumptions relevant to real life operations.

In a complex model there is more than one source of "error". For example, we may have:

perceived the "teal world" faultily, either omitting or misrepresenting certain factors; or

misjudged the degree of simplification adopted in the simulation representation; or

intended one decision rule, but due to the complexity of the model, written in another.

The first two points are those implied in discussion on validation, but the latter problem of verification is also common. We have already shown how the CARN model can permit sensitivity analysis to precede the simulation design and thus indicate where flexibility should be built into the model at an early and cheaper stage. There is also a use for the simpler model in verification. Suppose we refer to Cohen and Cyert 4 where regression between the observed and predicted values of the parameters is suggested as a check for validity. In place of the observations of reality, consider the comparison between CARN and simulation models shown in Figure 17. We note that there is a consistent bias toward underestimating the delay.

This occurs because (in the simulation model) the coachserved stands are allocated first thereby causing the early flights to suffer a worse average delay than is experienced when a purely random allocation of stands is used, as implied by the network coefficients. Furthermore, the traffic schedule is such that the expected payload of the early flights is approximately $22 \%$ greater than that realised on later flights. This reflects the high payload and large capacity units associated with the morning trans-Atlantic traffic.

The combination of these two factors means that the initial passenger delay in the simulation is larger than in the network approximation, particularly for early flights. $n_{i}=$ size of flight $i$ which selects a pier or $a$ coach for disembarkation

$d_{i}=$ delay associated with pier selected by flight $i$, the mean being $\bar{d}$

$c_{i}=$ delay associated with coached stand selected by flight $i$ (being a function of $n_{i}$ ), the mean of $c_{i}$ is $\bar{c}$

$a=$ proportion of flights selecting piers

1-a $=$ proportion of flights selecting coaches

A purely random selection of pier stands and of payloads between flights implies that the expected walking delay $\mathbf{E}(\mathrm{L})$ is

$$
E(L)=a \vec{d}+(1-a) \bar{c}
$$

But the realis ed average value is

$$
\bar{L}=\sum_{i} n_{i}\left(c_{i}+d_{i}\right) / \sum_{i} n_{i}
$$

where for a pier served stand selected by flight $i, c_{i}=0$ and for a coach served stand selected for flight $i, d_{i}^{i}=0$ so that when there are no piers utilised to serve flights (as would often happen for $i \leq 20$ ) a significant discrepancy between the results of equation (1), which maintains a random selection of piers, and equation (2) must occur.

The CARN program thus represents a useful and independent check of the assumptions in the simulation model, as well as serving as a guide for data collection.

Analysis

The importance of concomitant variables in improving the efficiency of a simulation has been reviewed by Gaver ${ }^{7}$. He gives a simple example based on a single queue, represented by a diffusion model. The technique may be exploited to even better advantage in this problem.

As an example, compare the variance of the mean delay, based on the one hand upon the regression of Figure 16 and on the other upon the CARN program. If we as sume that the CARN model gives a bias with a normal fluctuation superimposed, and that this is independent of the delay, then the bias may be represented as $\mathrm{N}(-6.36,5.79)$. At $95 \%$ we may assume confidence levels to the mean of $\pm_{1}$. 7 . In comparison the regression model gives confidence limits in the estimate of the mean are \pm 24 , where the level of congestion equals the observed mean value.

Thus the CARN estimate appears in this case to be 14 times more effective, which is equivalent to a reduction by a factor of 200 in the required computing time. 
One should perhaps note that this is the minimum of our regression confidence limits and that the CARN results still include the bias discussed earlier. This suggests that the estimate of saving represents a lower bound.

\section{Conclusions'}

This paper is a condensed version of a comprehensive study 12 . We have discussed some of the problems associated with the size of the study and suggested methods to alleviate them.

If the oijjective of the project is to produce a predictive or an operative model we suggest that simulation ought to be replaced by other methods, of which the CARN program is given as an example.

The speed of such simple methods, both in their construction and in computations, is their most significant characteristic. Remote terminals introduce a new level of accessability to computers and this must be matched by appropriate software, both in predictive and operative applications. These comments are especially relevant to the air transport industry. Air navigation charges are to be levelled on the airlines, and this must bring them into a closer involvement with the traffic control.

There is a natural progression from optimising individual flight plans to optimising the total transport system, and we hope that the arguments introduced here for the derivation of simple methods would be yalid in the wider field of integrated air and ground traffic control with its associated passenger movements.

\section{References}

1. Airports and Transport Aircraft 1970 Inter relations and Interface Problems. Conference proceedings Royal Aeronautical Society, London.

2. Carlin, A. and Park, R. E. (1969). A model of long delays at busy airports. RAND, p 4126.

3. Chamberlain, I. and Micka, S. (1969). Simulation and the airport problem clearing house

4. Cohen, K. J. and Cyert, R. M. (1961). Computer models in dyanic economics. Q. Jnl. Economics, no. 75, pp 112-127.

5. Fishman, G.S. and Kiviat, P.J. (1967). The analysis of simulation generated time series. Management Science, vol. 13, no. 7, pp 525-557.

6. Gafarin, A.V. and Ancker, C. J. (1966). Mean value estimation from computer simulation. Operations Research, vol. 14, no. 1, pp 25-44.
7. Gaver, B: P. Jr: $(1969)$ : Statistical Methods for improving simulatign efficiengy: Garnegie-Mellon Yniversity = Management Sciences Repert 169 .

8. Gebhard, R, $\mathbb{F}^{\prime}:(1964)$ A limiting distribution of antimate of mean queue lengths.

Operations Research, vol. 12, no. 6, pp 1000 1004.

9. Hills, P.R. (1971). HOCUS - the simulation technique for every manager. P-E Consulting Group, Egham, Surrey:

10. Hills, P.R. and Mathewson, S.C. $(1970)$ : A programming manual for SIMON simulation in FORTRAN: Management Enginesering Section, Imperial College, Eondgn:

11: Lave, R: F: and Thaha, H, A: (19,65): A program for simulating operation of an ever = head crane: Jnl: Industrial Engineering, vol. 16 , no. 2

12. Mathewson, S. G. $(1970)$. Simulation for an air terminal design: MPhil thesis, University of London:

13. Mckenney, $5:$ I: $(1968)$ : An approagh to simulatign model develgpment for improved planning: Fall Joint 6 gmputer Eonference, vol, 33 , part 1 :

14. Naylor, T: H. Balinty, J: L: , Burdigk, D, S. and Ghu; $(1966)$ : Gomputer sinulation techniques. Wiley, New York.

15. Naylor, T.H, and Finger, J.M. (1969). Vralidation computer simulation experiments with models of ecgnomic systems (ed, Naylor). Wiley, New: Fork.

16. Smith, E. E. and Murphy, J.T. (1968): Simulation of pas senger flows in piex fingers. Graduate Report of the University of Califernia, Berkeley.

17. Speas Associates (1968): Gomputer simulation for airport planping: Airport Wenld, vol. 1 , no. $1, \quad \mathrm{~PB}, 46-47$ ?

18: Tocher; 垈, D: $(1963)$, Fhe ant of simulation, English Universities Press:

19. Van Horn, R. L: (1969), Validation ef simulation results in The design of eomputer simulation experiments: (ed, Naylor, T. H:): Duke University Press: 


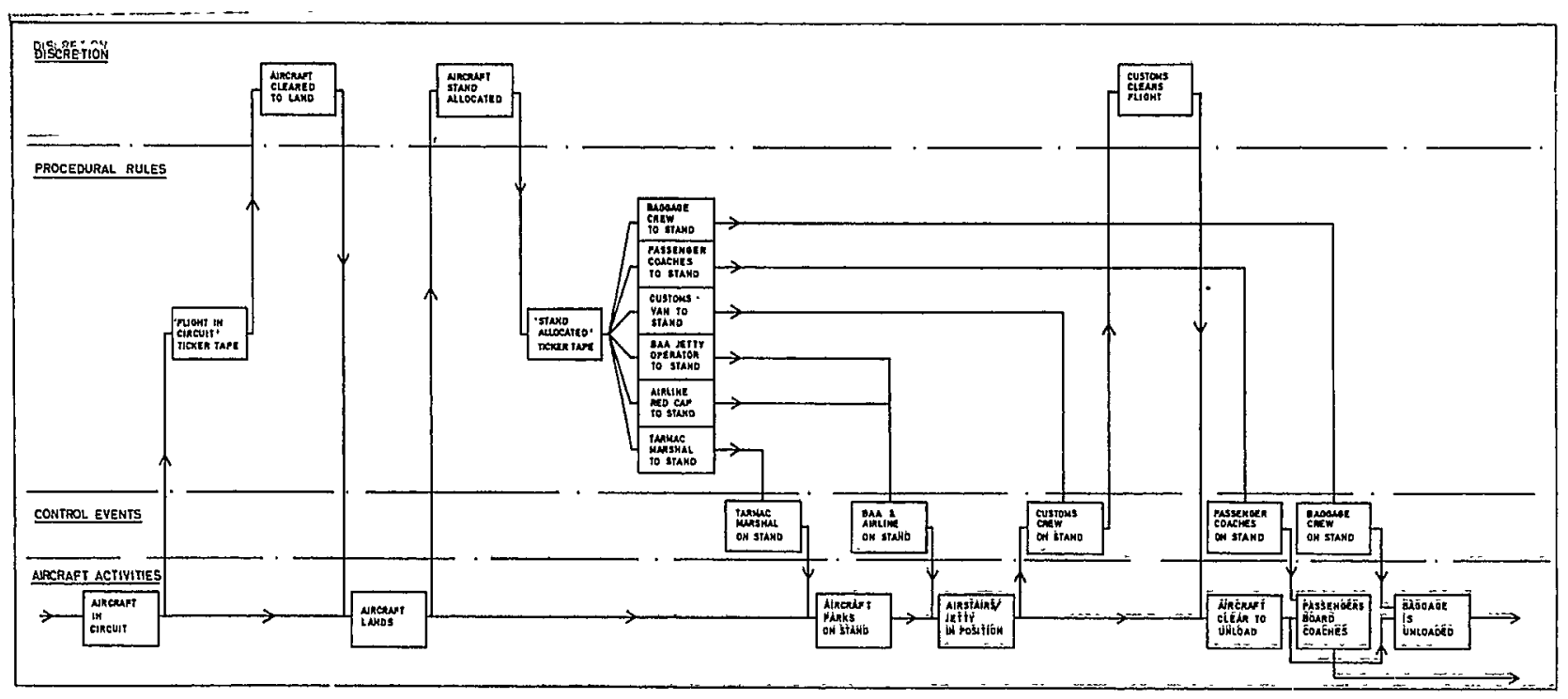

FIG. 1: ACTIVITIES TRIGGERED BY AIRCRAFT ARRIVALS

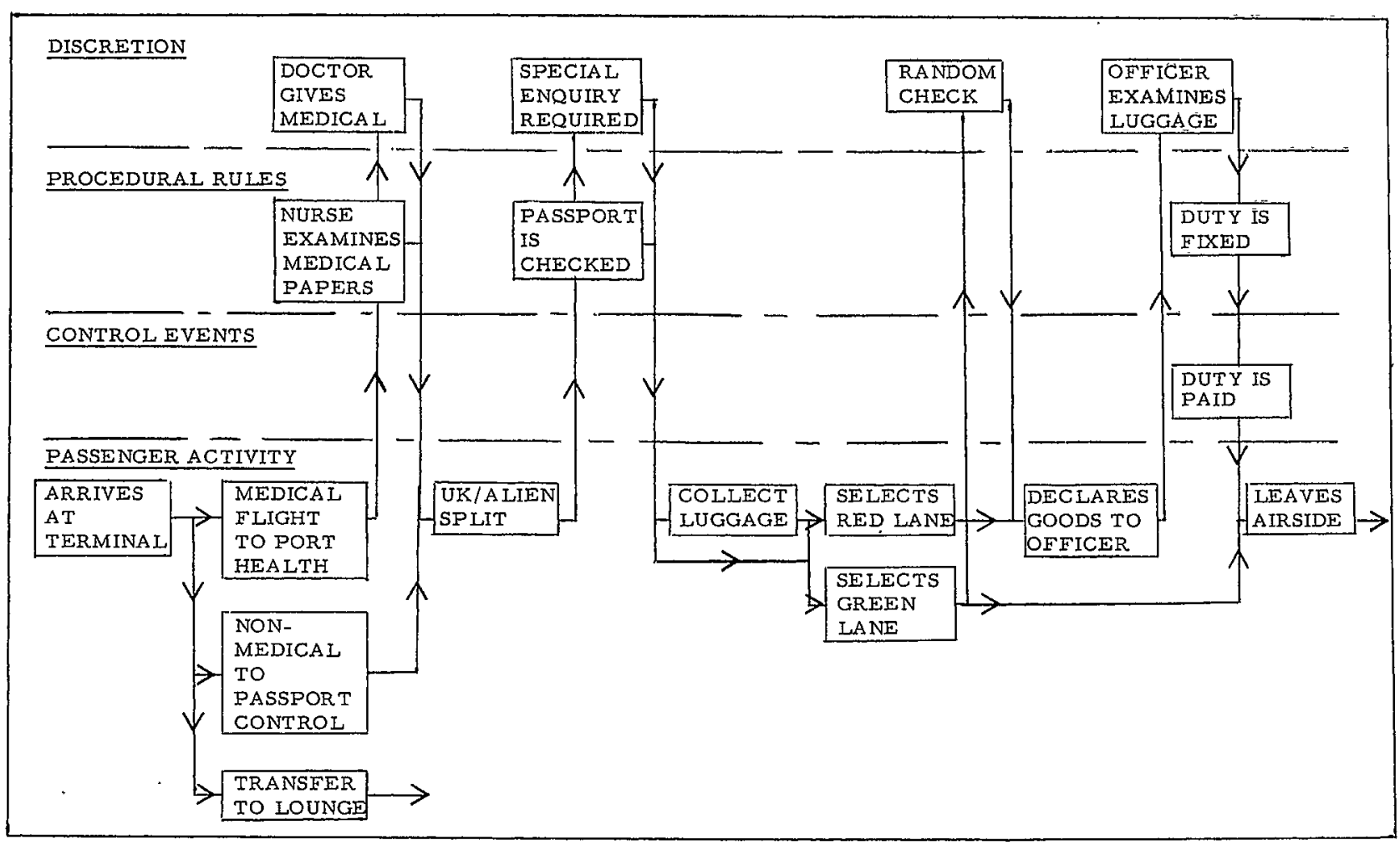

FIG. 2: PASSENGER ACTIVITY IN THE TERMINA L BUILDING 


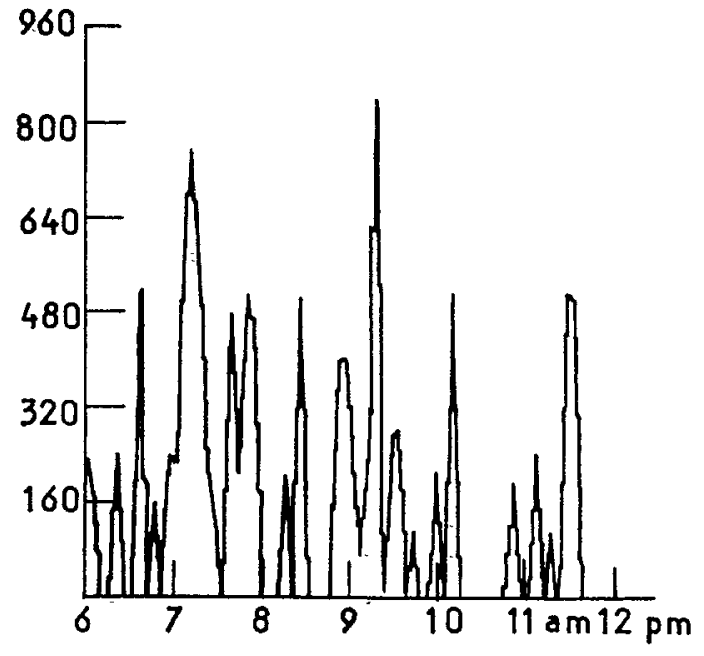

FIG. 3 : PASSENGER. ARRIVALS

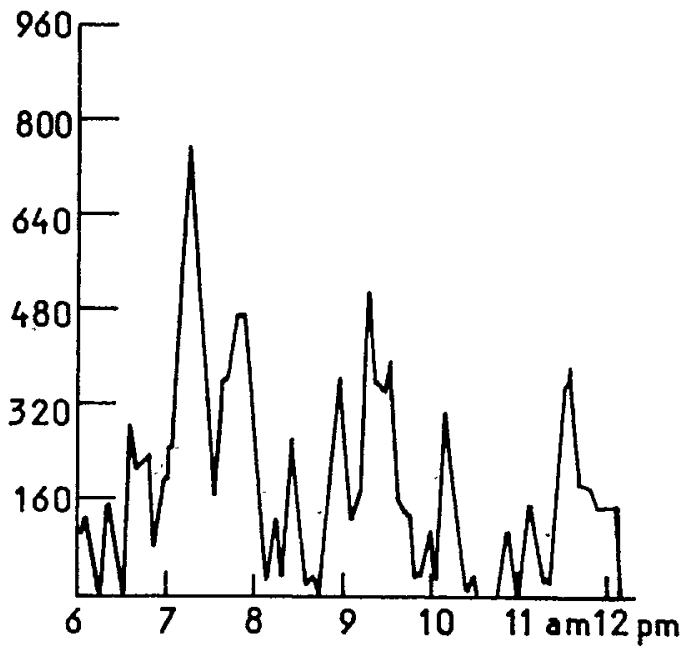

FIG. 4: PASSENGERS

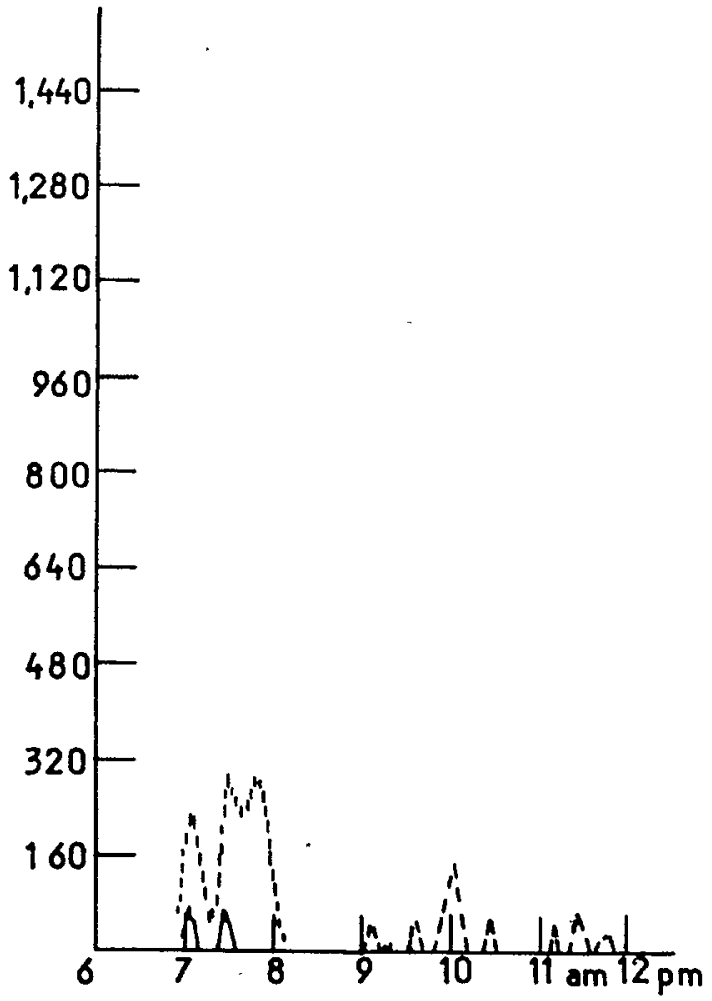

FIG. 5 : PASSENGER QUEUE AT PORT HEALTH

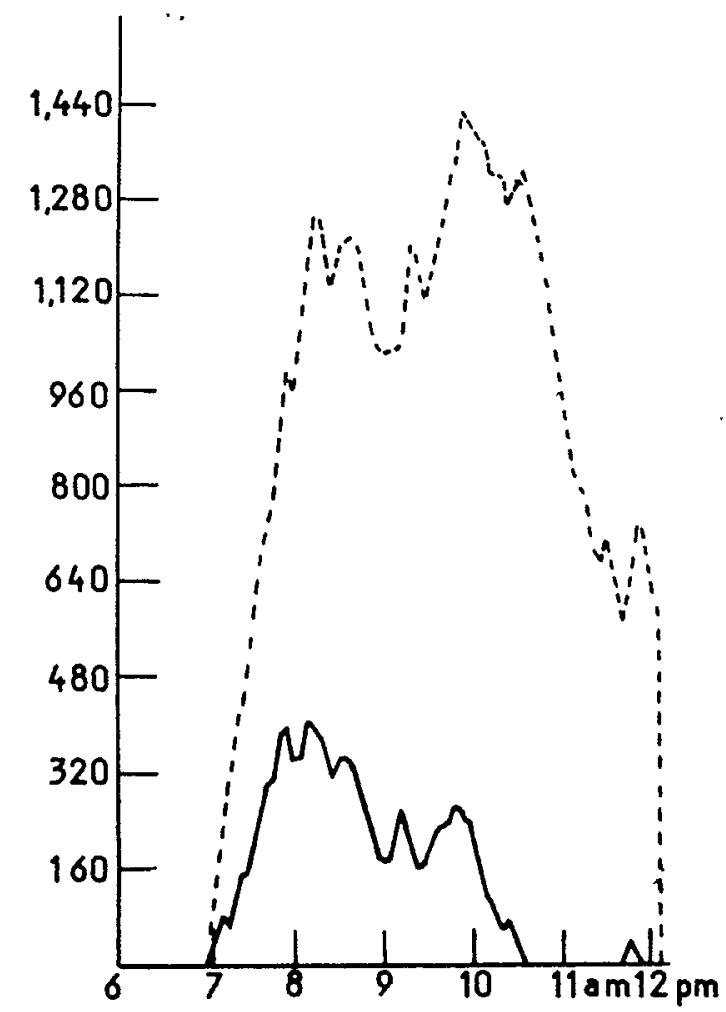

FIG.6: PASSENGER QUEUE AT ALIEN IMMIGRATION 


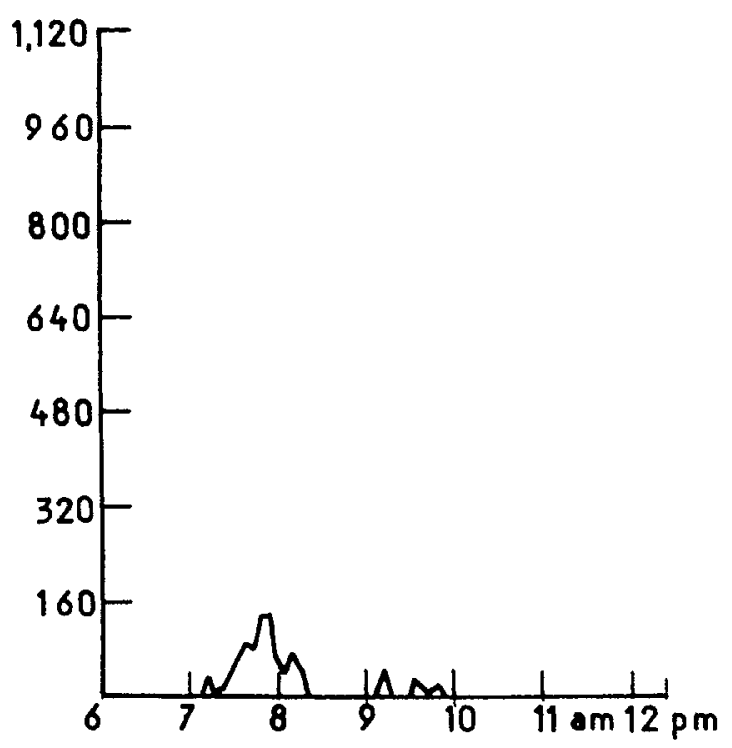

FIG.7: PASSENGER QUEUE AT UK IMMIGRATION

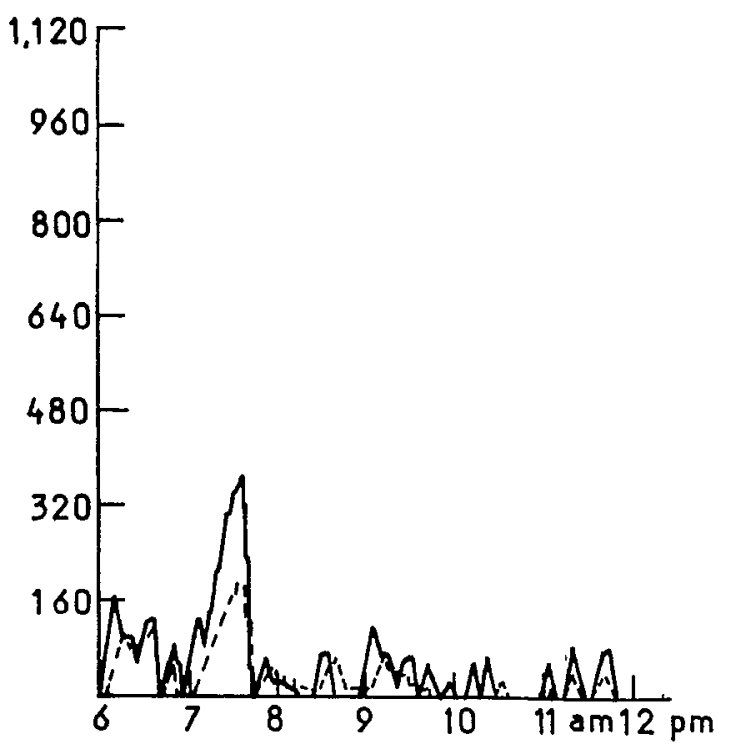

FI G. 8: PASSENGER QUEUE AT BAGGAGE RECLAIM

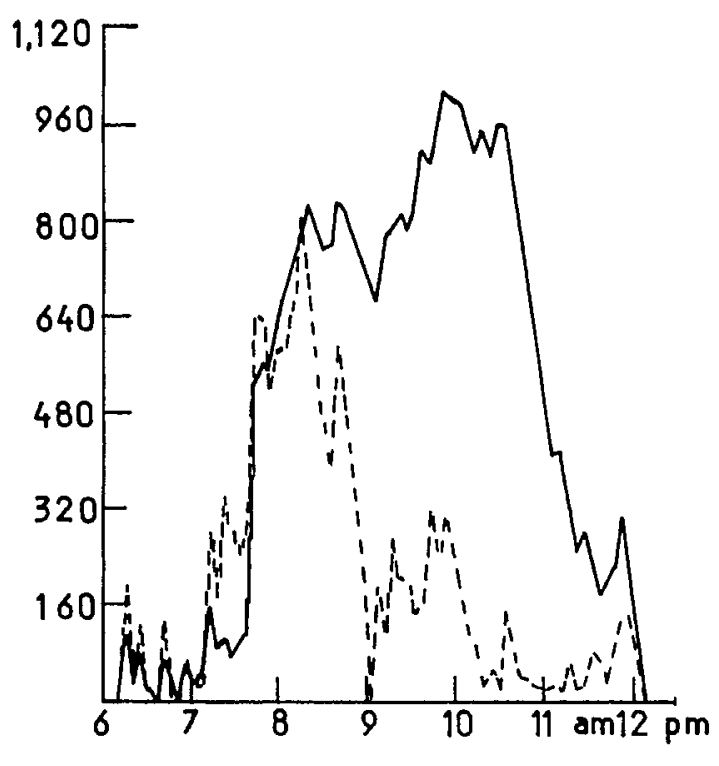

FIG. 9: $\frac{\text { PASSENGER QUEUE AT }}{\text { CUSTOMS }}$ 


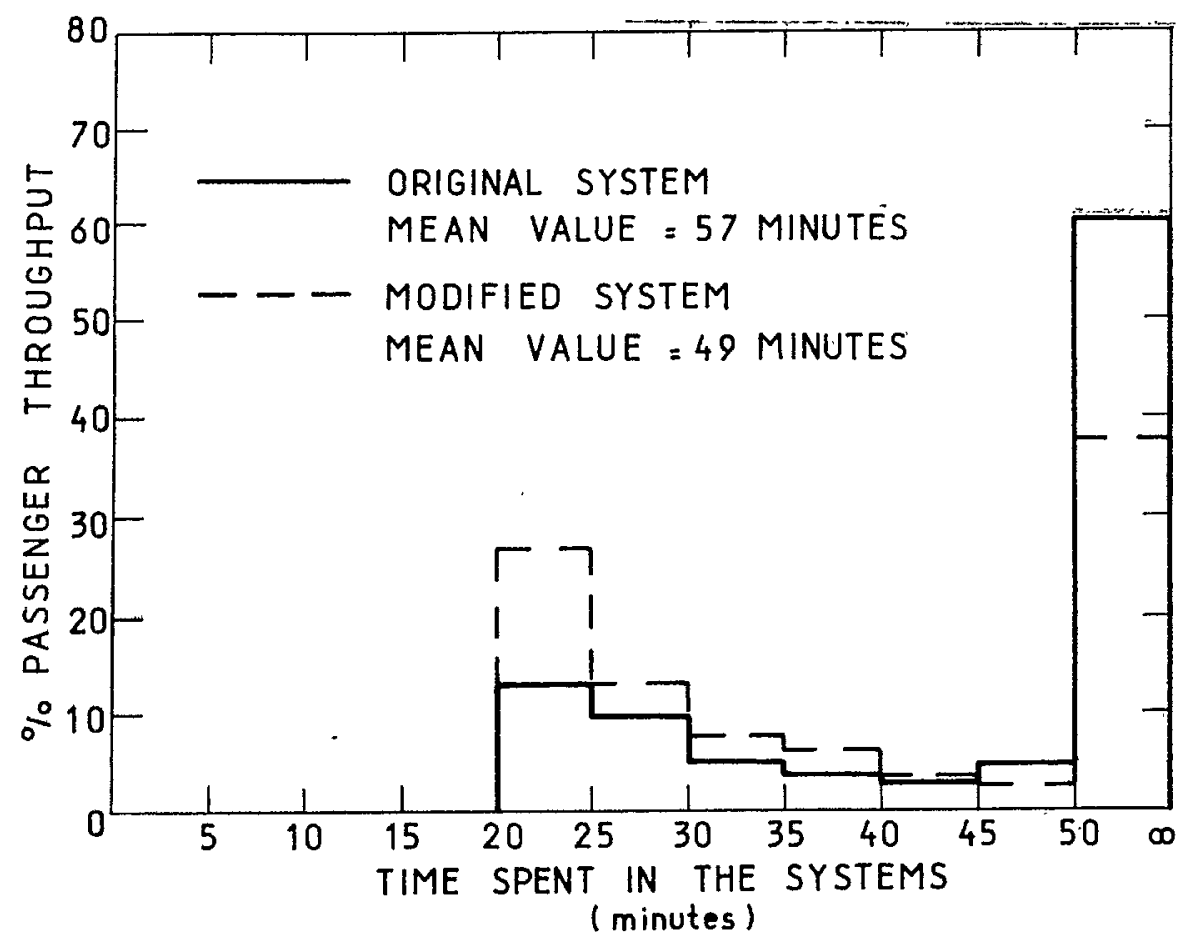

FIG. 10: HISTOGRAM OF PASSENGER WAITING TIME.

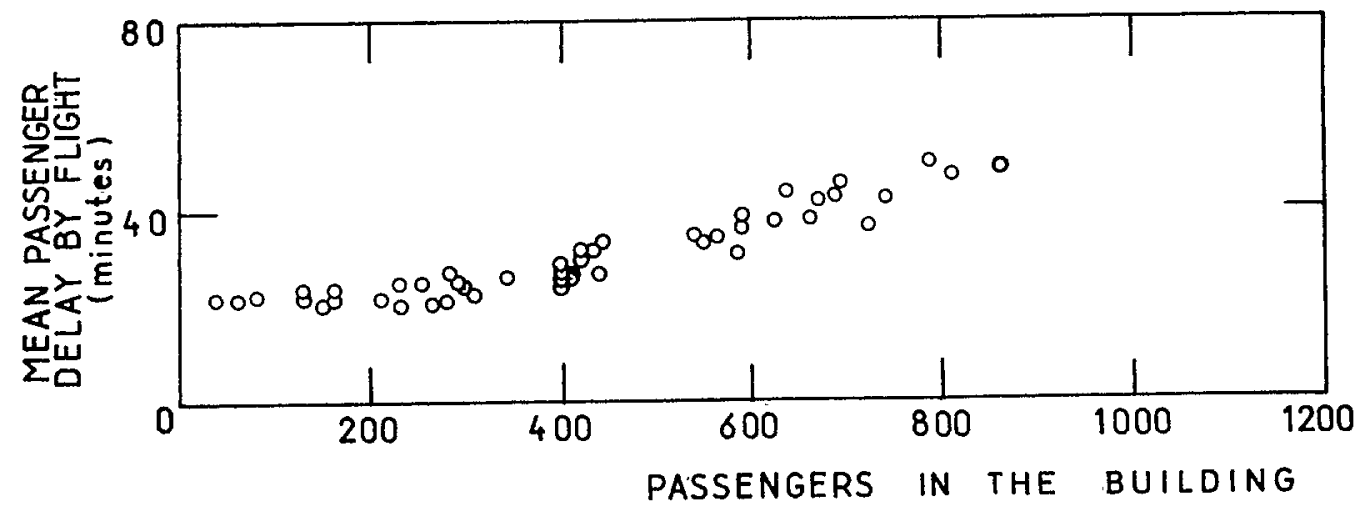

FIG. 11 : PASSENGER DELAYS IN AN UNCONGESTED SYSTEM 


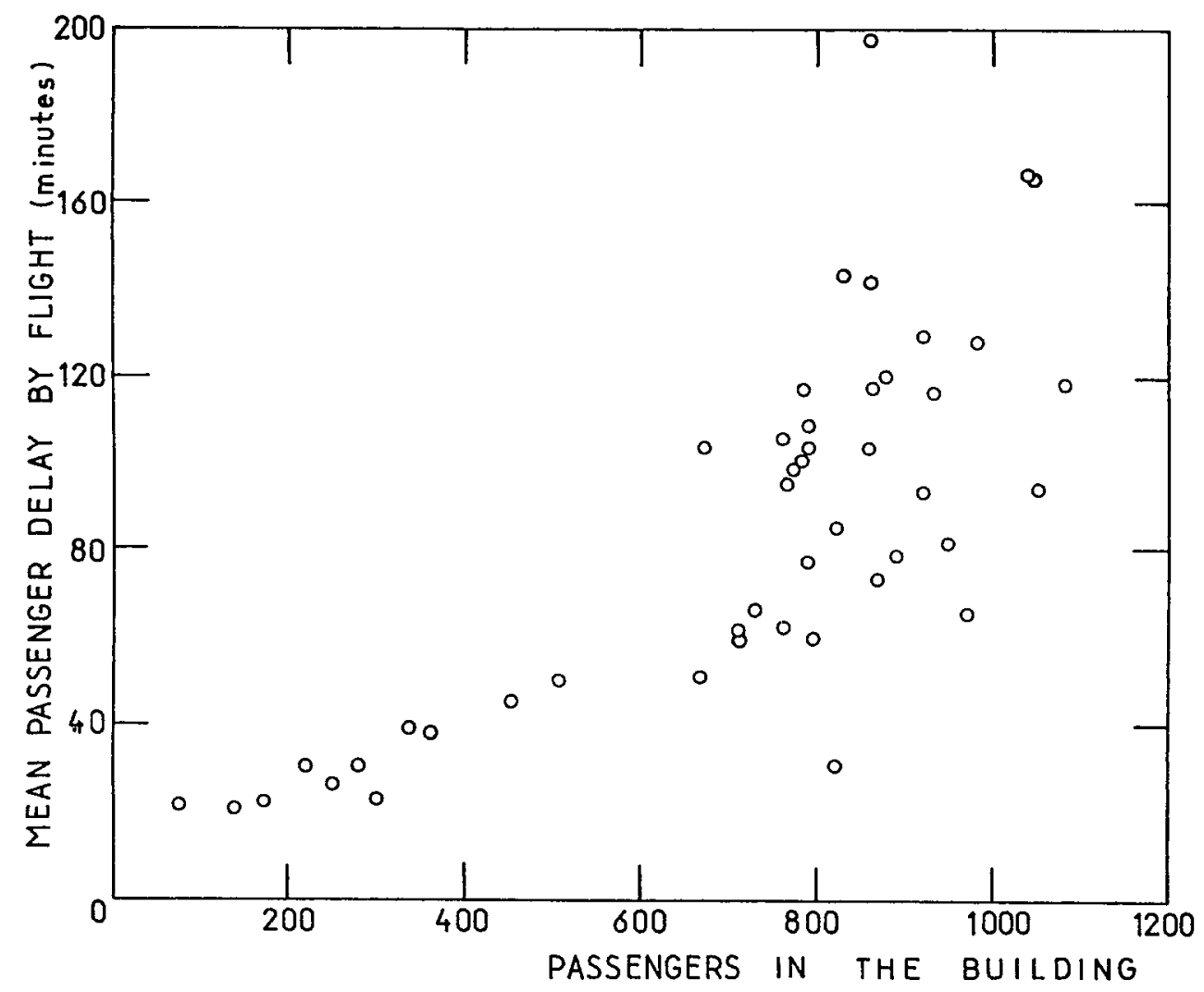

FIG. 12: PASSENGER DELAYS IN A CONGESTED SYSTEM.

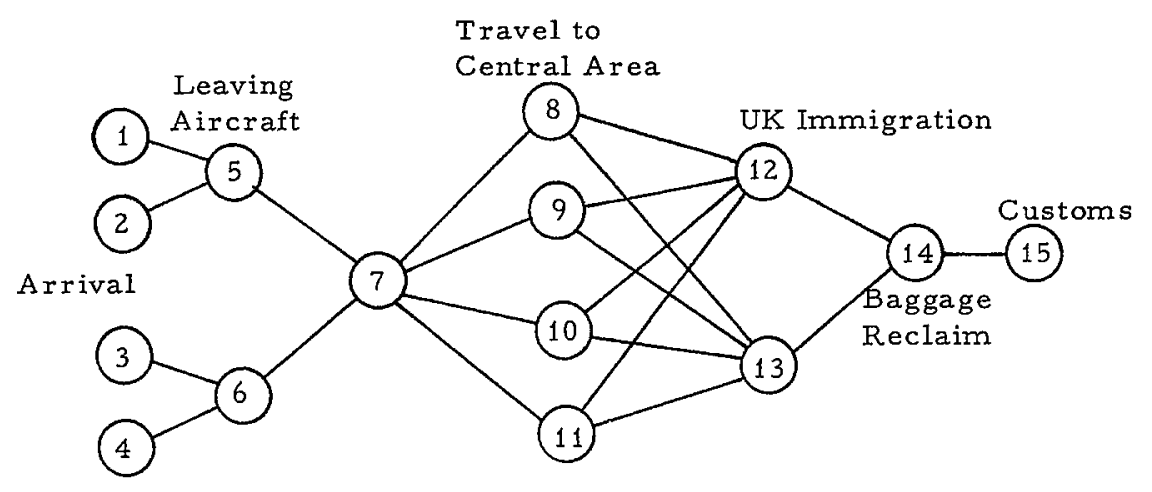

FIG. 13: AN ANA LOGOUS NETWORK 

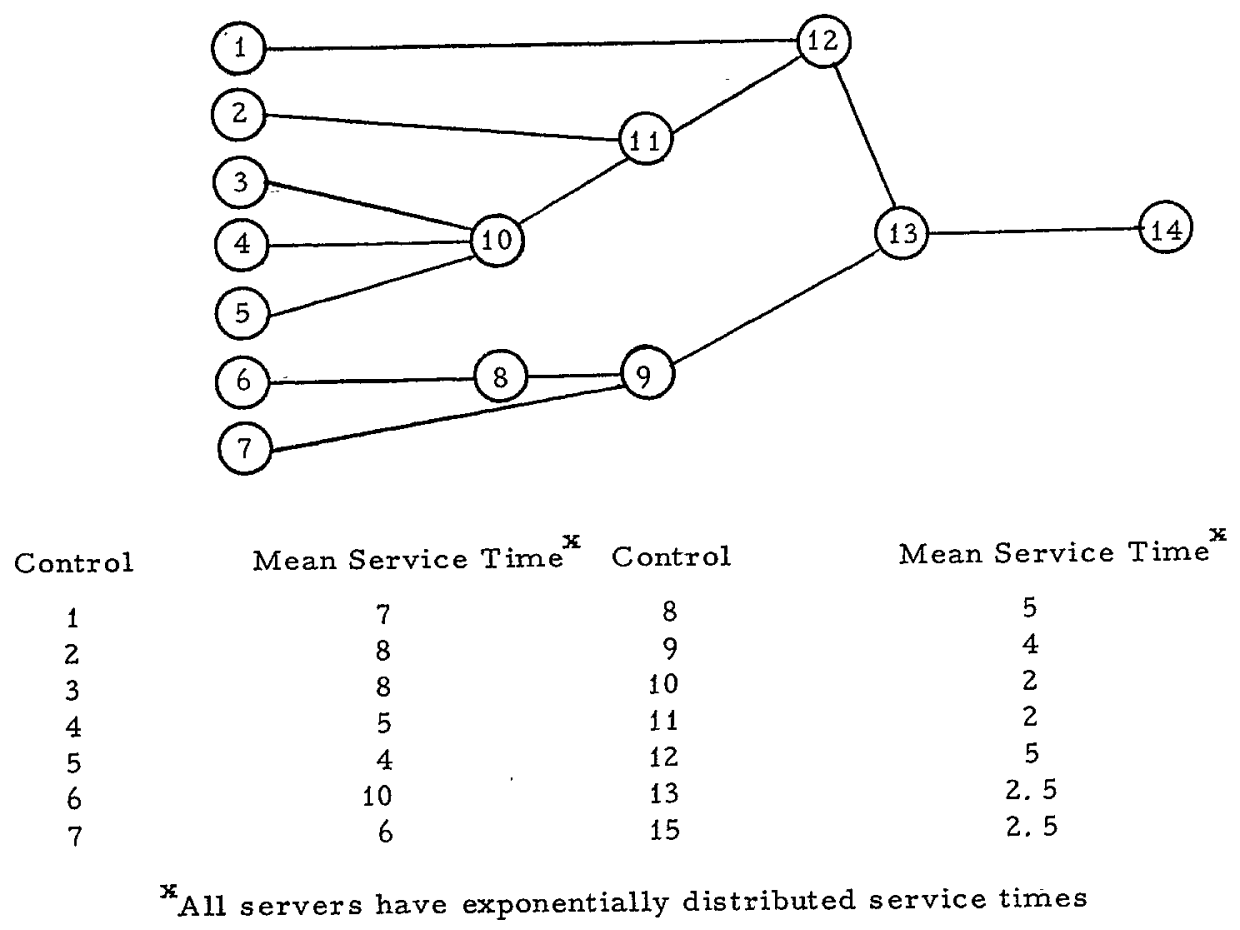

Input to 14 Node Network

Batch no, Entry control

$\begin{array}{rr}1 & 1 \\ 2 & 3 \\ 3 & 7 \\ 4 & 4 \\ 5 & 6 \\ 6 & 1 \\ 7 & 5 \\ 8 & 2 \\ 9 & 3 \\ 10 & 6 \\ 11 & 4 \\ 12 & 1 \\ 13 & 7 \\ 14 & 5 \\ 15 & 2 \\ 16 & 3 \\ 17 & 1 \\ 18 & 4 \\ 19 & 6 \\ 20 & 5\end{array}$

$\begin{array}{cc}\text { Batch size } & \text { Time of arrival } \\ 50 & 7 \\ 20 & 10 \\ 70 & 15 \\ 80 & 17 \\ 30 & 26 \\ 80 & 37 \\ 20 & 36 \\ 40 & 42 \\ 50 & 53 \\ 60 & 70 \\ 40 & 72 \\ 20 & 76 \\ 30 & 85 \\ 40 & 89 \\ 30 & 95 \\ 70 & 98 \\ 40 & 99 \\ 30 & 98 \\ 60 & 115 \\ 120 & 205\end{array}$

FIG. 14: DESCRIPTION OF THE 14 NODE NETWORK 


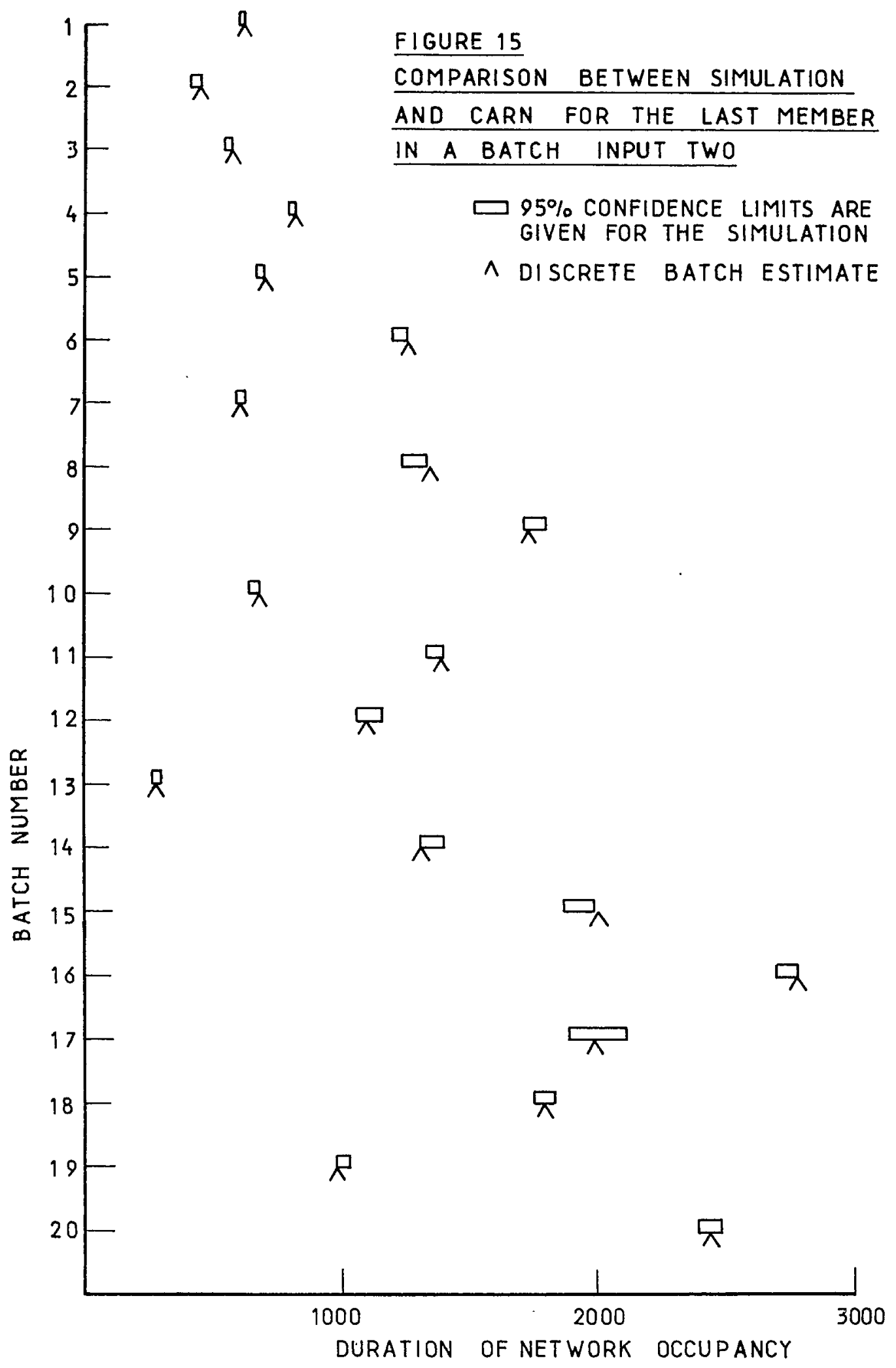




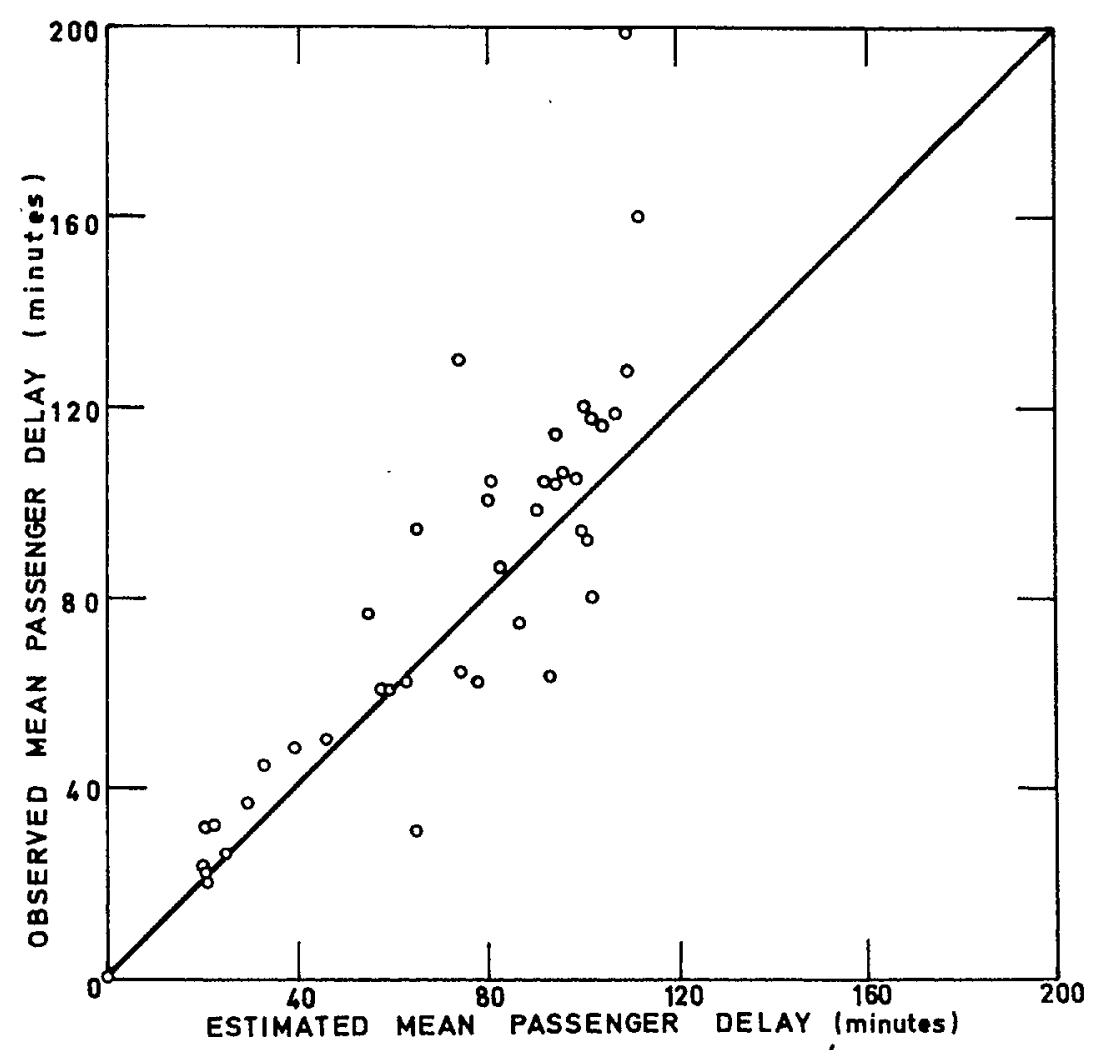

FIG.16: PREDICTION WITH A FALSE SPLIT IN THE UK/ALIEN PASSENGER ALLOCATION

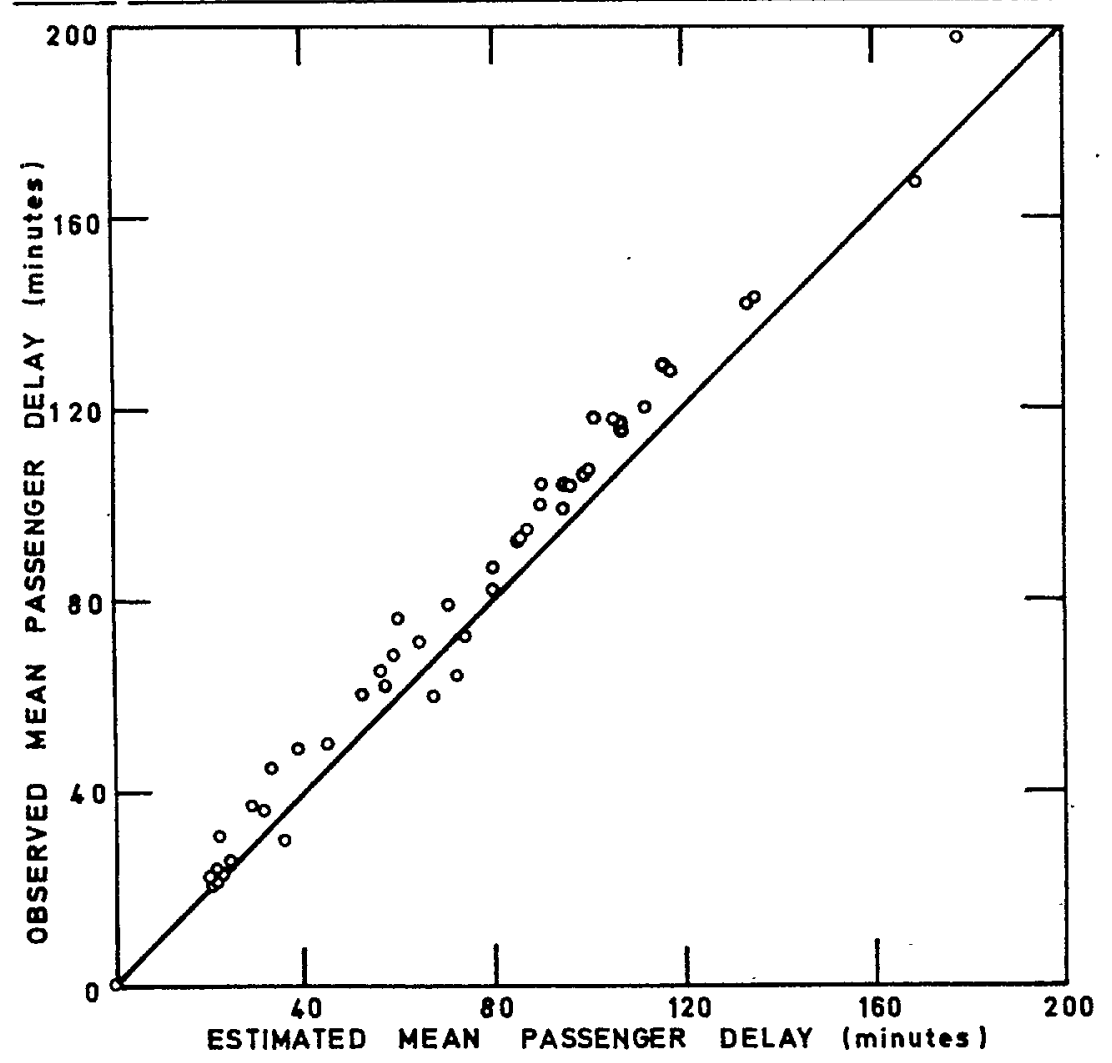

F1G. 17 : PREDICTION WITH A BIAS FROM UN-MATCHED FLIGHT/STAND ALLOCATION 


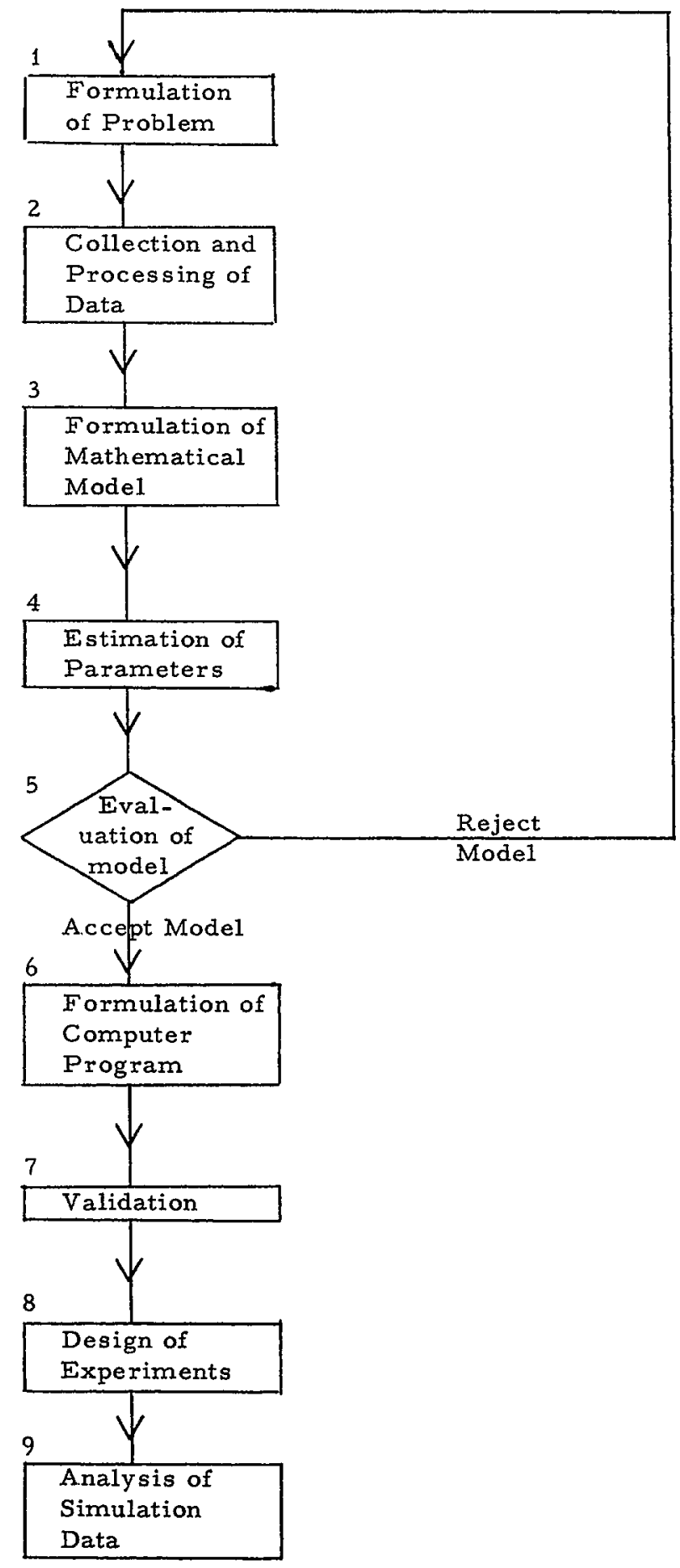

FIG. 18: STEPS IN A SIMULATION STUDY 


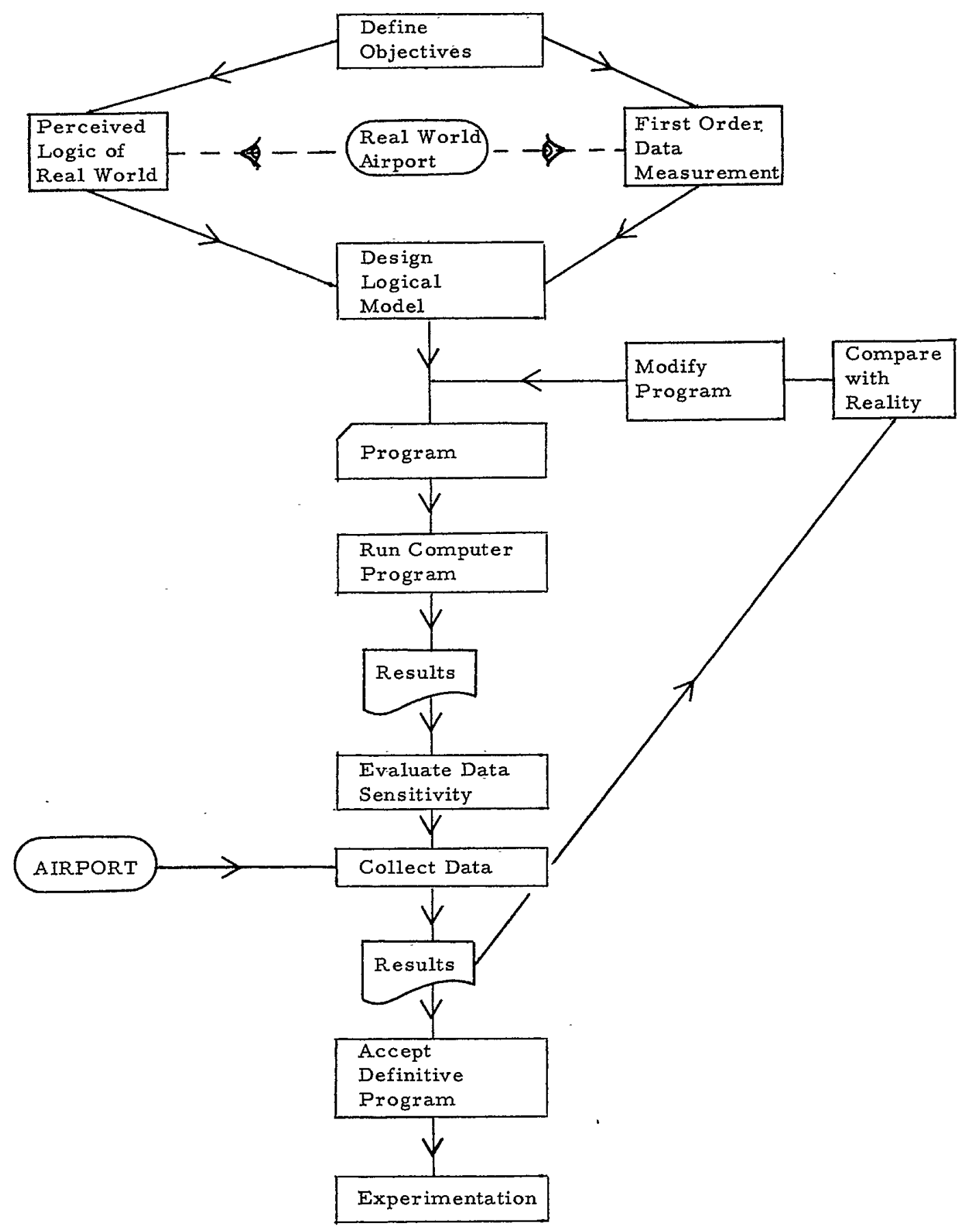

FIG. 19: PREFERRED STEPS IN A SIMULATION STUDY 